\title{
Rancang Bangun Sistem Pemadam Kebakaran Otomatis dan Dinamis Berbasis Mikrokontroler
}

\author{
Nola Sari Rahayu*, Wildian \\ . Jurusan Fisika, Fakultas Matematika dan Ilmu Pengetahuan Alam \\ Universitas Andalas, Kampus Limau Manis Padang, 25163 \\ *nola.rahayul@yahoo.com
}

\begin{abstract}
ABSTRAK
Telah dilakukan rancang bangun prototipe sistem pemadam kebakaran otomatis dan dinamis berbasis modul mikrokontroler Arduino Uno. Sumber api (berupa lilin) dideteksi menggunakan dua sensor temperatur IC LM35 yang dapat digerakkan melingkar horizontal oleh motor stepper berdasarkan program yang ditanamkan di mikrokontroller. Kedua sensor dipasang bersebelahan dengan sudut pisah $45^{\circ}$. Temperatur acuan yang telah ditetapkan sebagai indikator kebakaran adalah $50^{\circ} \mathrm{C}$.Jika sensor pertama mendeteksi temperatur $50^{\circ} \mathrm{C}$ maka sistem sensor akan bergerak ke arah sumber panas dalam arah dari sensor kedua ke sensor pertama, dan sebaliknya. Ketika sistem sensor ini telah berada tepat di dekat sumber api, mikrokontroler mengaktifkan saklar pompa air untuk menyemprotkan air. Prototipe ruangan yang dibangun berukuran $60 \mathrm{~cm}$ × $60 \mathrm{~cm}$ x $60 \mathrm{~cm}$. Sistem yang dirancang mampu menyiramkan air hingga ketitik sumber api yang berada hingga $18 \mathrm{~cm}$ di atas lantai ruangan simulasi.
\end{abstract}

Kata kunci : Arduino Uno, temperatur, sensor LM35

\section{ABSTRACT}

The prototype of automatic and dynamic fire-extinguishing system based on Arduino Uno microcontroller module has been done. Fire source (wax) is detected using two IC LM35 temperature sensors that can be driven horizontally by a stepper motor based on the program embedded in the microcontroller. Both sensors are mounted adjacent to the separation angle $45^{\circ}$ The reference temperature specified as the indicator of fire is $50{ }^{\circ} \mathrm{C}$. If the first sensor detects a temperature of $50{ }^{\circ} \mathrm{C}$ then the sensor system will move toward the heat source in the direction from the second sensor to the first sensor, and the other. When the sensor system is located right near the source of the fire, the microcontroller activates the water pump switch to spray water. The prototype of the room that was built measuring $60 \mathrm{~cm} x 60 \mathrm{~cm} x$ $60 \mathrm{~cm}$. The system is designed to sprinkle water to the point of fire source that is located $18 \mathrm{~cm}$ above the floor of the simulation room.

Keywords: Arduino Uno, temperature, sensor LM3

\section{PENDAHULUAN}

Bencana dapat terjadi dimana saja, baik di daerah pantai, desa ataupun kota. Salah satu jenis bencana yang sering terjadi di daerah perkotaan adalah kebakaran. Badan Nasional Penanggulangan Bencana (BNPB) mendefenisikan kebakaran sebagai situasi dimana bangunan pada suatu tempat seperti rumah/pemukiman, pabrik, pasar, gedung dan lain-lain dilanda api yang menimbulkan korban dan kerugian (BNPB, 2016).

Ada 3 faktor penyebab timbulnya api. Pertama, adanya bahan yang mudah terbakar seperti benda berbahan padat, cair, maupun gas (minyak, bensin, kertas, kayu, tekstil, dan lainlain). Kedua, adanya temperatur tinggi yang disebabkan oleh sumber panas seperti sinar matahari, listrik hubungan singkat (kortsleting), reaksi kimia dan lain sebagainya. Ketiga,adanya oksigen $\left(\mathrm{O}_{2}\right)$ yang memiliki kandungan cukup untuk terjadinya suatu reaksi api (IPD, 2017).

Kasus kebakaran seringkali terjadi pada rumah atau bangunan yang daam keadaan tak berpenghuni, misalnya rumah yang ditinggalkan oleh pemiliknya dan bangunan perkantoran pada malam hari. Surjanto (2010), merancang sistem basis kontrol menggunakan personal computer (PC) yang bersifat multi-purpose dan multi-task dan masih bersifat statis (tidak bergerak). Jafar (2013), menggunakan mikrokontroler ATmega328 untuk sistem pengontrolan yang bersifat otomatis dengan menggunakan detektor nyala api (flame detector), sistem detektor yang dipasang masih bersifat statis. Pada penelitian Suryatini (2013), merancang sebuah robot yang dilengkapi detektor nyala api, UVTron, sensor PING Ultrasonik range finder, dan blower. Robot dapat mendeteksi api hingga jarak 5 meter, dan memadamkan api dengan cara meniup (menggunakan kipas) yang dapat menimbulkan pembesaran api. Penelitian ini 
merancang sebuah sistem pemadam kebakaran otomatis dan dinamis dengan menggunakan dua buah sensor temperatur untuk mencari sumber api. Sistem sensor digerakkan motor stepper yang dikontrol oleh mikrokontroler. Api dipadamkan dengan menyemprotkan air secara menyebar dari atas.

\section{METODE}

\subsection{Perancangan diagram blok}

Diagram blok sistem pemadam kebakaran otomatis dan dinamis dapat dilihat pada Gambar 1. Prinsip kerja dari pemadam kebakaran yaitu diawali oleh pengukuran temperatur pada ruangan simulasi yang berukuran $60 \mathrm{~cm}$ x $60 \mathrm{~cm}$ x $60 \mathrm{~cm}$ dengan menggunakan dua buah sensor. Sensor dipasang bersebelahan dengan posisi sensor pertama sebelah kanan dan sensor kedua berada disebelah kiri dengan sudut $45^{\circ}$ dengan ketinggian $45 \mathrm{~cm}$ dari dasar ruangan. Sensor akan bergerak sesuai dengan syarat yang telah dibuat, jika sensor pertama mendeteksi nilai temperatur lebih tinggi, maka sensor bergerak kekanan, sebaliknya jika sensor kedua mendeteksi nilai temperatur lebih besar dari sensor pertama, sensor bergerak memutar ke arah kiri. Sensor mendeteksi temperatur diatas $37^{\circ} \mathrm{C}$, maka sensor akan bergerak memutar pada satu bidang melingkar dengan motor stepper seperti pada Gambar 3. Sensor dapat berhenti jika telah menemukan temperatur paling tinggi, dengan menandakan kedua sensor memiliki nilai yang mendekati sama diatas $50^{\circ} \mathrm{C}$ dan mikrokontroler memproses sinyal masukan dari pengukuran temperatur dan nilai temperatur ditampilkan pada layar LCD. Mikrokontroler juga mengaktifkan alarm untuk memperingati bahwa adanya api dan mengaktifkan pompa untuk melakukan proses peyiraman api.

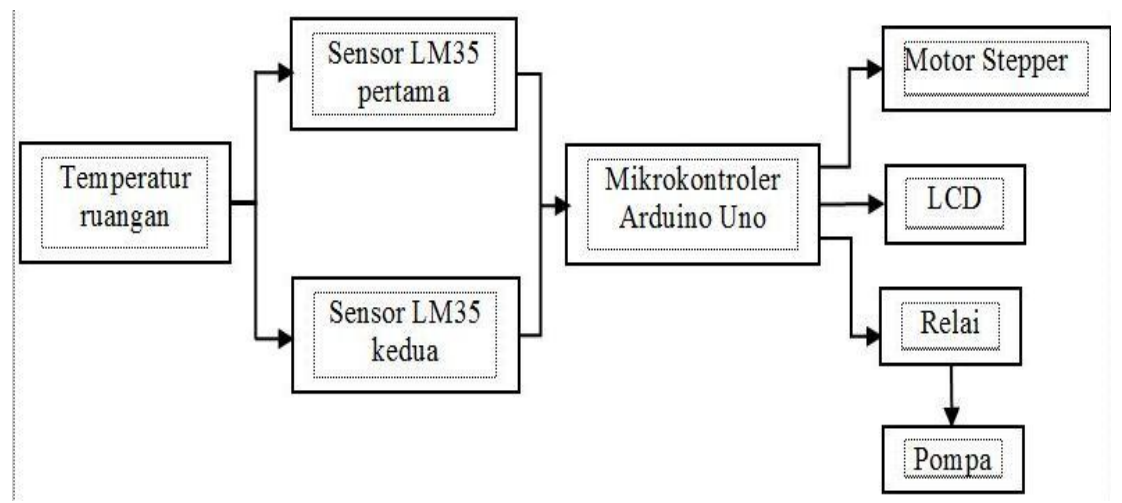

Gambar 1 Diagram blok sistem kontrol pemadam kebakaran

\subsection{Perancangan perangkat lunak system}

Sistem kontrol pemadam kebakaran memiliki beberapa langkah kerja, yang pertama nilai temperatur awal ruangan langsung dideteksi oleh kedua sensor LM35 pada saat api dinyalakan. Kedua,nilai temperatur yang terukur diproses pada mikrokontroler dan hasilnya ditampilkan pada layar LCD. Ketiga, keluaran dari sensor akan diproses apabila nilai temperatur yang diukur diatas $30^{\circ} \mathrm{C}$, sensor akan diputar menggunakan motor stepper. Arah pemutaran sensor berdasarkan posisi sensor yang memiliki nilai tertinggi.Keempat, ketika kedua sensor memiliki nilai temperatur mendekati sama $50^{\circ} \mathrm{C}$, alarm berbunyi untuk memberikan peringatan.Kelima, ketika alarm telah berbunyi, secara otomatis pompa menyala dan melakukan proses penyiraman api pada ruangan.Perancangan diagram alir perangkat lunak dapat dilihat seperti Gambar 2. 


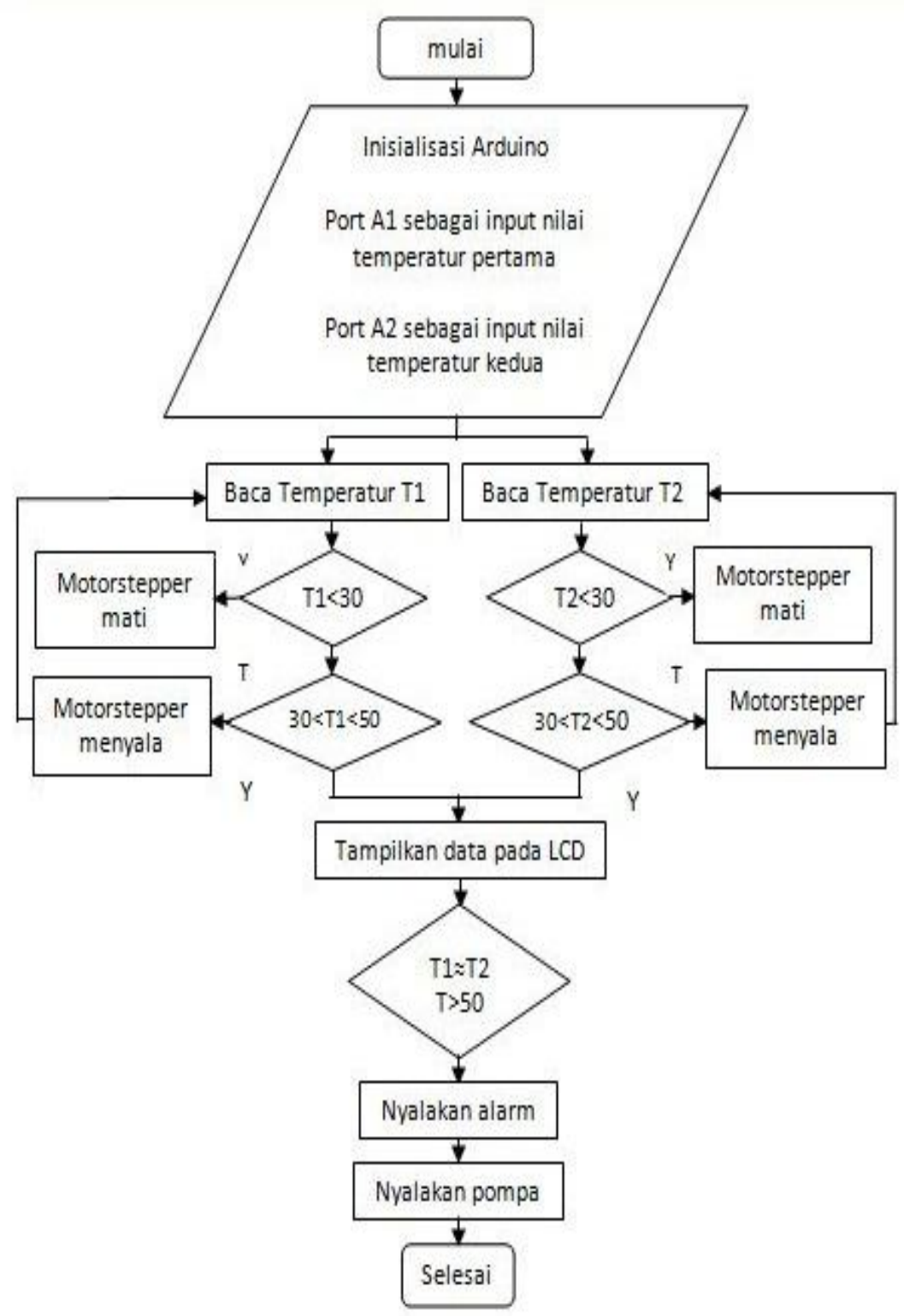

Gambar 2 Diagram alir program pengukuran temperature

Program yang ditanamkan ke Arduino berupa pengukuran nilai temperatur yang terbaca oleh kedua sensor yang akan dibandingkan untuk melihat hasil temperatur yang terukur dan dapat melakukan proses pergerakkan memutar pada sensor berdasarkan pembacaan nilai temperatur yang tertinggi diantara kedua sensor tersebut, jika salah satu sensor memiliki nilai temperatur tertinggi dari sensor yang satunya lagi, maka sensor akan bergerak ke arah sensor yang memiliki nilai tertinggi tersebut,

\subsection{Perancangan alat keseluruhan}

Pada metode ini, rangkaian pertama terdiri dari dua buah sensor LM35 yang dipasang pada motor stepper yang berada dibagian atas didalam ruangan, dalam ruangan tersebut diatas motor stepper juga terdapat sebuah shower yang digunakan untuk alat penyiram dengan metode penyebaran air. Rangkaian kedua, terdiri dari rangkaian sistem kontrol yang diletakkan di bagian atas di luar ruangan berupa Mikrokontroler Arduino Uno, LCD, relay, dan buzzer. Rangkaian ketiga, sebuah tabung air yang dipasangkan pompa didalamnya dan pompa tersebut dihubungkan ke tabung shower menggunakan pipa sebagai saluran yang mengalir dari bak air. Rancangan alat secara keseluruhuan dapat dilihat pada Gambar 3. 


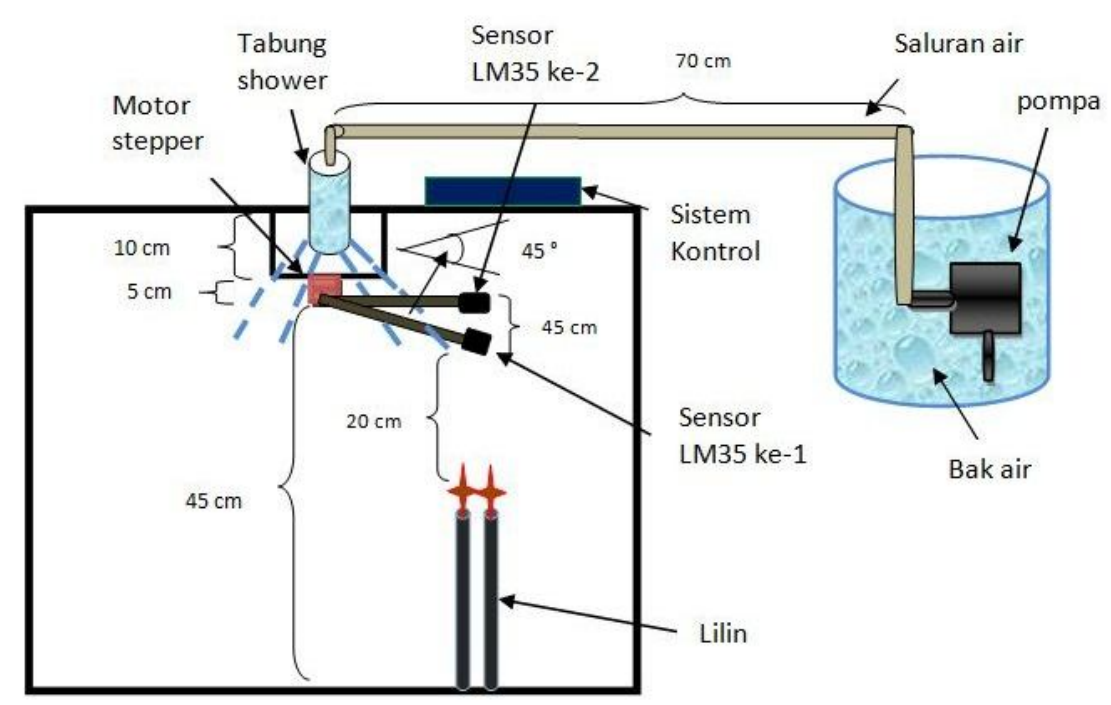

Gambar 3 Rancangan alat keseluruhan

\section{HASIL DAN DISKUSI}

\subsection{Hasil pengukuran nilai temperatur sensor pertama berdasarkan variasi jarak}

Grafik pengukuran nilai temperatur terhadap variasi jarak antara sensor dan keberadaan titik api dapat dilihat pada Gambar 4, hal ini memperlihatkan bahwa sensor melakukan pengukuran temperatur pertama pada saat temperatur ruangan bernilai $37^{\circ} \mathrm{C}$ dimulai pada jarak $30 \mathrm{~cm}$.

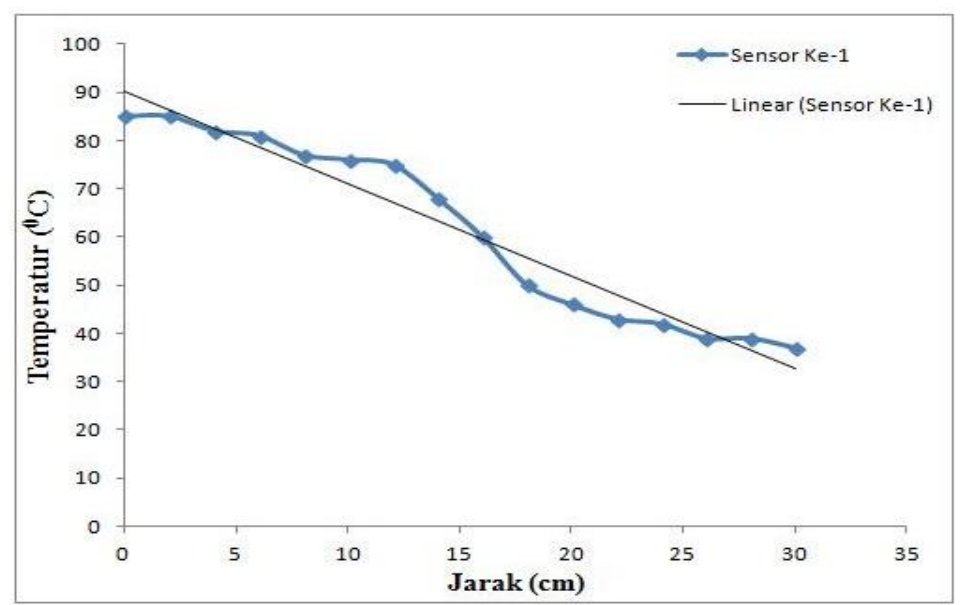

Gambar 4 Grafik nilai temperatur sensor pertama terhadap variasi jarak antara sensor dan titik keberadaan api

Waktu pengukuran dilakukan saat api telah dinyalakan selama 3 menit. Temperatur terus naik akibat terjadinya proses perpindahan kalor melalui udara di ruangan sehingga sensor dapat menyerap kalor yang dipancarkan oleh api sehingga semakin lama api menyala semakin panas temperatur pada ruangan tersebut. Hal ini menandakan bahwa proses terjadinya kebakaran merupakan perpindahan kalor radiasi. Sensor pertama memperoleh nilai temperatur awal yang lebih tinggi, sehingga sensor bergerak ke arah kanan, dan membuktikan bahwa semakin dekat sensor dengan keberadaan titik api. Nilai temperatur yang terbaca oleh sensor pertama terus naik sampai pada jarak $18 \mathrm{~cm}$ dengan nilai temperatur sebesar $50^{\circ} \mathrm{C}$. Kenaikan temperatur lebih tinggi terjadi pada jarak $16 \mathrm{~cm}$ dengan kenaikan $10^{\circ} \mathrm{C}$ dari temperatur sebelumnya, kenaikan terus terjadi hingga pada jarak $12 \mathrm{~cm}$ sebesar $75^{\circ} \mathrm{C}$. Disaat sensor berada di jarak $10 \mathrm{~cm}$ kenaikan temperatur tidak terlalu tinggi, diakibatkan pada jarak tersebut nilai temperatur yang terbaca memiliki panas yang sama, sehingga pengukuran terakhir sensor 
berada di posisi atas titik api, dengan ketinggian $18 \mathrm{~cm}$ dari permukaan api yang ditandai dengan perputaran sensor yang telah berada pada titik $0 \mathrm{~cm}$.

\subsection{Hasil pengukuran nilai temperatur sensor kedua berdasarkan variasi Jarak}

Dari Gambar 5 dapat dilihat bahwa pada sensor kedua juga mampu mendeteksi temperatur pada ruangan, dengan pengukuran awal pada sensor sebesar $34^{\circ} \mathrm{C}$ pada jarak $30 \mathrm{~cm}$. Hal ini menandakan bahwa sensor kedua tidak berada didekat sumber titik api, sehingga pengukuran sensor kedua lebih rendah dari sensor pertama.

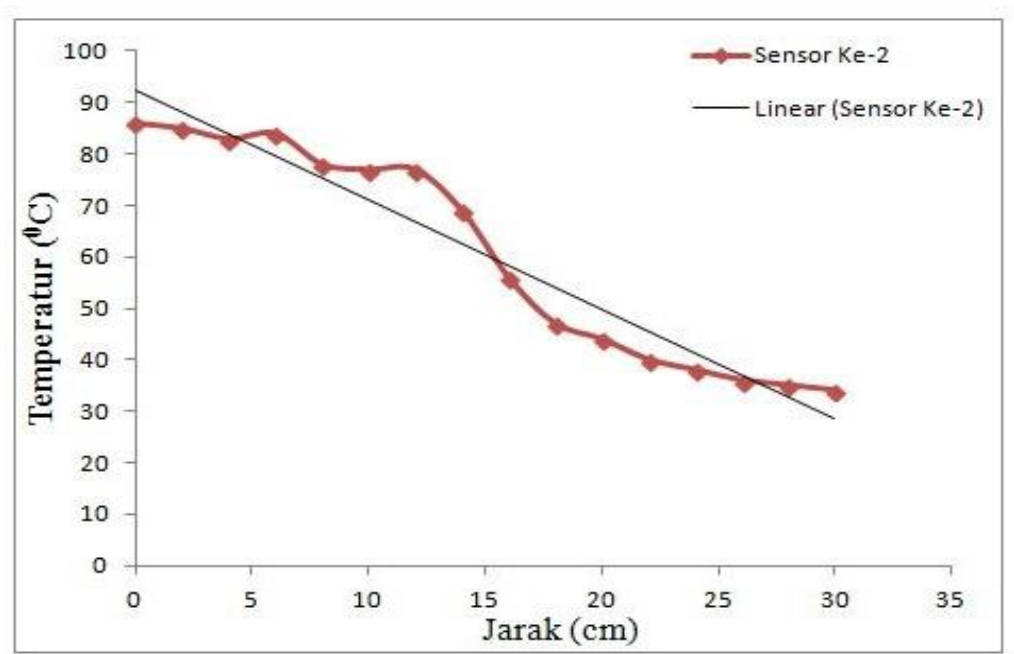

Gambar 5 Grafik nilai temperatur sensor kedua terhadap variasi jarak antara sensor dan titik keberadaan api

Sitem kerja sensor kedua sama dengan sensor pertama, akan bergerak memutar satu bidang melingkar sesuai dengan sensor yang memiliki temperatur tertinggi. Pada sensor kedua kenaikan temperatur pada jarak $30 \mathrm{~cm}$ hingga $18 \mathrm{~cm}$ tidak terlalu tinggi, tetapi pada jarak ke 18 $\mathrm{cm}$ hingga $12 \mathrm{~cm}$ kenaikan temperatur mengalami kenaikan yang cukup besar hingga mencapai $10^{\circ} \mathrm{C}$. Setelah sensor berada di jarak $10 \mathrm{~cm}$ dari keberadaan sumber titik api, sensor mengalami kenaikan temperatur yang tidak terlalu tinggi.

\subsection{Perbandingan nilai temperatur kedua sensor berdasarkan variasi jarak}

Perbandingan nilai temperatur dari kedua sensor LM35 yang digunakan dapat dilihat pada Gambar 6. Dapat disimpulkan bahwa awal pengukuran temperatur sensor kedua memiliki nilai temperatur yang lebih tinggi dari sensor kedua, dikarenakan sensor pertama berada di dekat sumber api. Untuk hasil akhir antara kedua sensor ini memiliki nilai yang hampir sama saat berada diatas sumber api, dengan hasil pengukuran sensor pertama memiliki nilai temperatur $85^{\circ} \mathrm{C}$ dan sensor kedua memiliki nilai temperatur sebesar $86^{\circ} \mathrm{C}$, hanya memiliki perbedaa $1^{\circ} \mathrm{C}$ saja. Pada temperatur tersebut, sistem kontrol mulai bekerja dengan menyalakan alarm dan memyalakan pompa untuk melakukan proses penyiraman. Hal ini membuktikan bahwa alat pemadam kebakaran otomatis dan dinamis yang telah dirancang tersebut, mampu bekerja dengan baik untuk melengkapi penelitian yang sebelumnya untuk pemadaman api kebakaran yang masih bersifat statis (tidak bergerak) dan proses pemadaman yang masih mengggunakan kipas, sehingga hal tersebut dapat menimbulkan pembesaran api. Pada alat ini dibuat dengan kelebihan alat yang otomatis dan dinamis, yang mana sensor dapat bergerak untuk mendeteksi dan mencari sumber api, serta proses pemadaman yang sudah menggunakan sistem penyiraman air yang disemprot secara menyebar dan dapat bekerja tanpa pengontorolan dari manusia. 


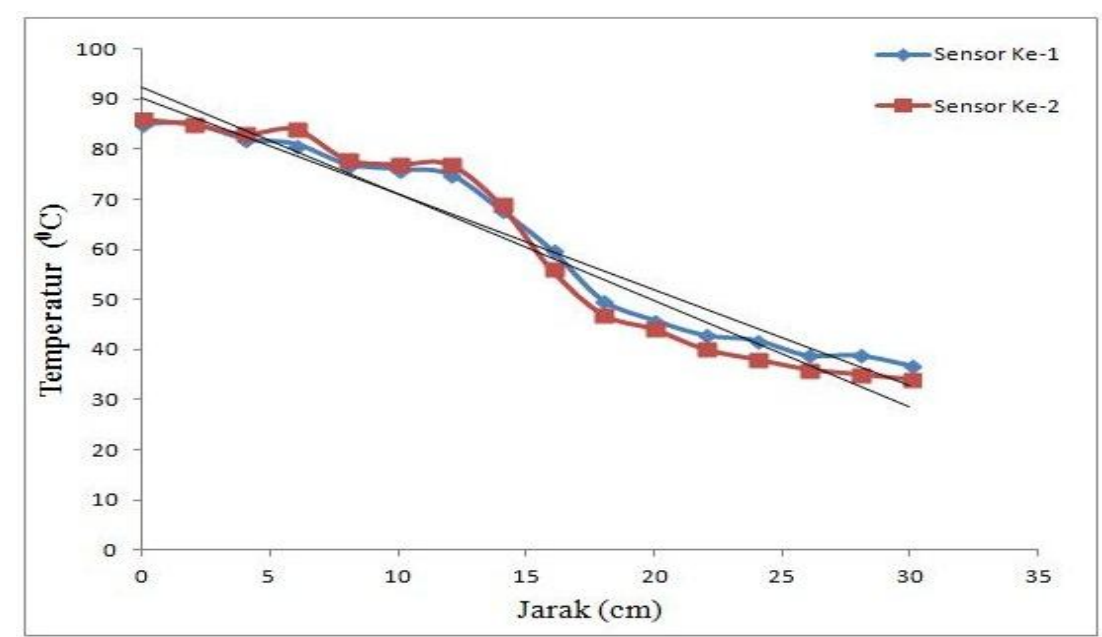

Gambar 6 Perbandingan nilai temperatur kedua sensor terhadap perubahan Jarak antara sensor dan titik keberadaan api.

\section{KESIMPULAN}

Alat pemadam kebakaran otomatis dan dinamis inimenggunakan dua buah sensor temperatur dan telah dapat mengukur temperatur pada ruangan. Sensor berputar menggunakan motor stepper serta dapat berhenti jika temperatur yang terdeteksi oleh sensor mencapai $50{ }^{\circ} \mathrm{C}$. Ketika sensor telah berada di dekat sumber api, mikrokontroler mengaktifkan saklar pompa dan melakukan proses penyiraman ke sumber api hingga batas ketinggian $18 \mathrm{~cm}$ di atas lantai dasar ruangan, sehingga alat pemadam kebakaran ini mampu beker ja secara otomatis dan dinamis.

\section{DAFTAR PUSTAKA}

Jafar, A., "Alat Pemadam Kebakaran Otomatis Berbasis Mikrokontroler Arduino Uno ATmega328P”, Jurnal, UPI, Bandung, 2013.

Surjanto, A., "Rancang Bangun Model Sistem Pemadam Kebakaran Otomatis pada Ruangan", Jurnal Elektron 2(1), 2010.

Suryatini, F., "Robot Cerdas Pemadam Api Menggunakan Ping Ultrasonic Range Finder dan UVTron Flame Detector Berbasis Mikrokontroler ATmega128”, Jurnal UPI, 2013.

BNPB, "Defenisi dan Jenis Bencana", http://www.bnpb.go.id/home/defenisi, 2016, diakses pada Maret 2017.

IPD, "5 Jenis Penyebab Kebakaran dan Alat Pemadam Api yang Tepat, IPD-Free", http://infopromodiskon.com/news/detail/275/5-jenis-penyebab-kebakaran-dan-alatpemadam-api-yang-tepat, 2017, diakses pada Agustus .2017. 